\title{
Diagnostic accuracy of cardiovascular magnetic resonance for patients with suspected cardiac amyloidosis: a systematic review and meta-analysis
}

\author{
Lei Zhao, Zhuang Tian and Quan Fang*
}

\begin{abstract}
Background: This study is a systematic review and meta-analysis of the diagnostic value of cardiovascular magnetic resonance (CMR) in cardiac amyloidosis (CA).

Methods: A wide variety of electronic databases were searched for studies of CMR that reported the diagnostic accuracy in patients with suspected CA. Research manuscripts were subjected to further systematic review and meta-analysis. Methodological evaluation was performed under the guidance of the Quality Assessment of Diagnostic Accuracy Studies -2 (QUADAS-2). Heterogeneity was assessed, and a random-effects model was used to assess the diagnostic effects of CMR on pooled sensitivity, pooled specificity, and summary receiver operating characteristics (SROC).

Results: Seven studies that reported the performance of CMR for CA were included in the present systematic review, among which five studies (257 patients) that evaluated the diagnostic accuracy of late gadolinium enhancement (LGE) CMR were analyzed in the present meta-analysis. Heterogeneity was observed only in specificity. A summary sensitivity and specificity of $85 \%$ (95 \% Cl: 77-91\%) and $92 \%$ (95\% Cl: 83-97 \%) indicated a high diagnostic accuracy of LGE for CA. The AUC of SROC curve was 0.9530 , suggesting that LGE is an effective way of diagnosing patients with possible cardiac involvement in amyloidosis.

Conclusions: LGE-CMR seems to have a relatively high diagnostic accuracy for amyloidosis patients with possible cardiac involvement. Combined CMR techniques may provide important information for the selection of suitable therapy.
\end{abstract}

Keywords: Cardiac amyloidosis, Cardiac magnetic resonance, LGE, Meta-analysis

\section{Background}

The heart, like any organ in the body is susceptible to amyloid deposition. When this occurs in the heart, cardiac amyloidosis (CA) results. Although more than 30 types of protein can cause amyloid, only two types commonly deposit in the ventricular myocardium: amyloid light chain (AL) and amyloid transthyretin (ATTR). The heart is sometimes the only or early manifestation of systemic amyloidosis [1]. Deposition of amyloid precursor

\footnotetext{
* Correspondence: quanfangxjn2013@163.com

Department of Cardiology, Peking Union Medical College Hospital, Peking Union Medical College and Chinese Academy of Medical Sciences, No.1

Shuaifuyuan, WangfujingDongcheng District, Beijing 100730, China
}

proteins which then aggregate into amyloid fibrils in the extracellular space causes separation and distortion of the existing tissues and eventually causes irreversible cardiac dysfunction $[2,3]$. This may occur in the myocardium, pericardium, small vessels and conduction system. The result is a restrictive cardiomyopathy with early diastolic dysfunction and later systolic dysfunction, conduction disease including sudden death and, occasionally ischaemia (with arterial involvement) [4].

CA is relatively under-diagnosed, especially wild type ATTR in older people with multisystem diseases. One potential reason is that the symptoms and signs of $\mathrm{CA}$ 
such as fatigue, low exercise tolerance and occasionally syncope with progressive diastolic and systolic dysfunction may be nonspecific, particularly in the early phases, resulting in delayed diagnosis and potentially missed therapeutic options. New treatments are available targeting the precursor proteins, including newer chemotherapy regimes and a variety of approaches to reduce transthyretin as a precursor, with further developments in the preclinical phase $[5,6]$. For this reason, earlier diagnosis of CA is a major clinical goal [7].

Currently, the main steps in the clinical evaluation of patients with CA involve suspicion, detection, and classification. Suspicion may be raised by multisystem involvement (carpal tunnel, renal impairment etc.). Laboratory investigations may confirm the diagnosis, classify the CA, trace the specific protein precursor and appraise the stage of cardiac involvement including pump function [8]. Currently, the most common examination procedures used to evaluate patients or conditions associated with CA include endomyocardial biopsy (EMB), electrocardiography (ECG), echocardiography and cardiac magnetic resonance (CMR) with some nuclear tests contributing (bone scintigraphy for ATTR, SAP scan for AL - but these are not widely available).

In CA, myocardial tissue histology stands as the gold standard, revealing the accumulation of amyloid proteins and fibers in the extracellular space. Histologically, EMB is initially stained using Congo Red where deposits may look pale red but show apple-green birefringence under cross-polarized light. Immunohistochemistry (IHC) or mass-spectrocopy can definitively subtype the amyloid fibrils [4]. However, the invasive nature of EMB and related high-risk complications are barriers, as is the specialist nature of IHC and mass spectroscopy. Besides, as the lack of standardization on the definition of what constitutes CA, in some cases these is a need to use some ancillary imaging and clinical findings to ensure the pathological diagnosis. In addition, EMB is classified in the class IIa recommendation [9].

ECG Low -voltages is a classical feature of CA [10]. But it provides a low -sensitivity and -specificity diagnosis of CA. This may be due in part to interference from other coexisting conditions, such as obesity, hypothyroidism, and pulmonary diseases, but up to $25 \%$ of ATTR subjects have left ventricular hypertrophy. Under echocardiograph, the CA classical feature (a "brilliant" speckled appearance of myocardium) is a poor discriminator. Biventricular hypertrophy with disproportionate long axis impairment and restriction is more specific, but still has overlap, particularly in early disease [11].

CMR, a noninvasive mean of assessing amyloid burden, makes use of a superconducting magnet with ECG gating to measure the structure and function of the heart analogous to echocardiography. In addition, myocardial tissue characterisation detects tissue pathology [12]. In particular, the late gadolinium enhancement (LGE) has a characteristic pattern in amyloid with subendocardial, later transmural LGE and difficulty nulling. This latter issue appears resolved with the phase-sensitive inversion recovery (PSIR) LGE sequence and it has potential to be a key technique for the diagnosis of patients with potential CA [13]. Several studies have compared the diagnostic accuracy of CMR to that of EMB. However, they focused on different parameters and used different cutoff values in diagnostic tests, which limit their usefulness in the assessment of CA. For this reason, a systematic review was conducted to help evaluate the diagnostic aspects of CMR in patients with suspected CA.

\section{Methods}

\section{Data sources}

This systematic review was carried out under the guideline of the Cochrane Collaboration's Diagnostic Test Accuracy Group. Search strategies were developed to identify all the relevant studies published in the Pubmed, Embase, the Cochrane Library, Biosis Preview, ISI Web of Science, and China National Knowledge Infrastructure up to April 20, 2015. Medical subject headings and full text were searched for references to $\mathrm{CA}$ and magnetic resonance imaging to systematically locate these publications in any language. The details of the search strategies are provided in the additional files. The citations of eligible publications and reviews were also checked. Requirements were limited to human trials.

\section{Study selection and data collection}

The first author (LZ) conducted the initial literature search of titles and abstracts. Upon further scrutiny, two reviewers (LZ, ZT) led the retrieval of the full texts of relevant manuscripts independently. A third reviewer (QF) resolved all the disagreements and discrepancies that occurred during these processes through deep discussions. The following inclusion criteria were defined in advance: (1) a diagnostic accuracy test was included; (2) patients with at least suspected CA; (3) the diagnostic accuracy of CMR was evaluated regardless of acquisition protocol used; (4) EMB, clinical criteria, or both served as the reference tests; (5) the absolute numbers of true positive, false positive, true negative, and false negative results could be derived. All the articles that met these criteria were considered eligible. Duplicate and overlapping publications were excluded. Conference abstracts and research manuscripts that could not be obtained in their entirety or from which essential information was missing were also excluded. Diagnostic accuracy details, study methods, results, and additional information on 


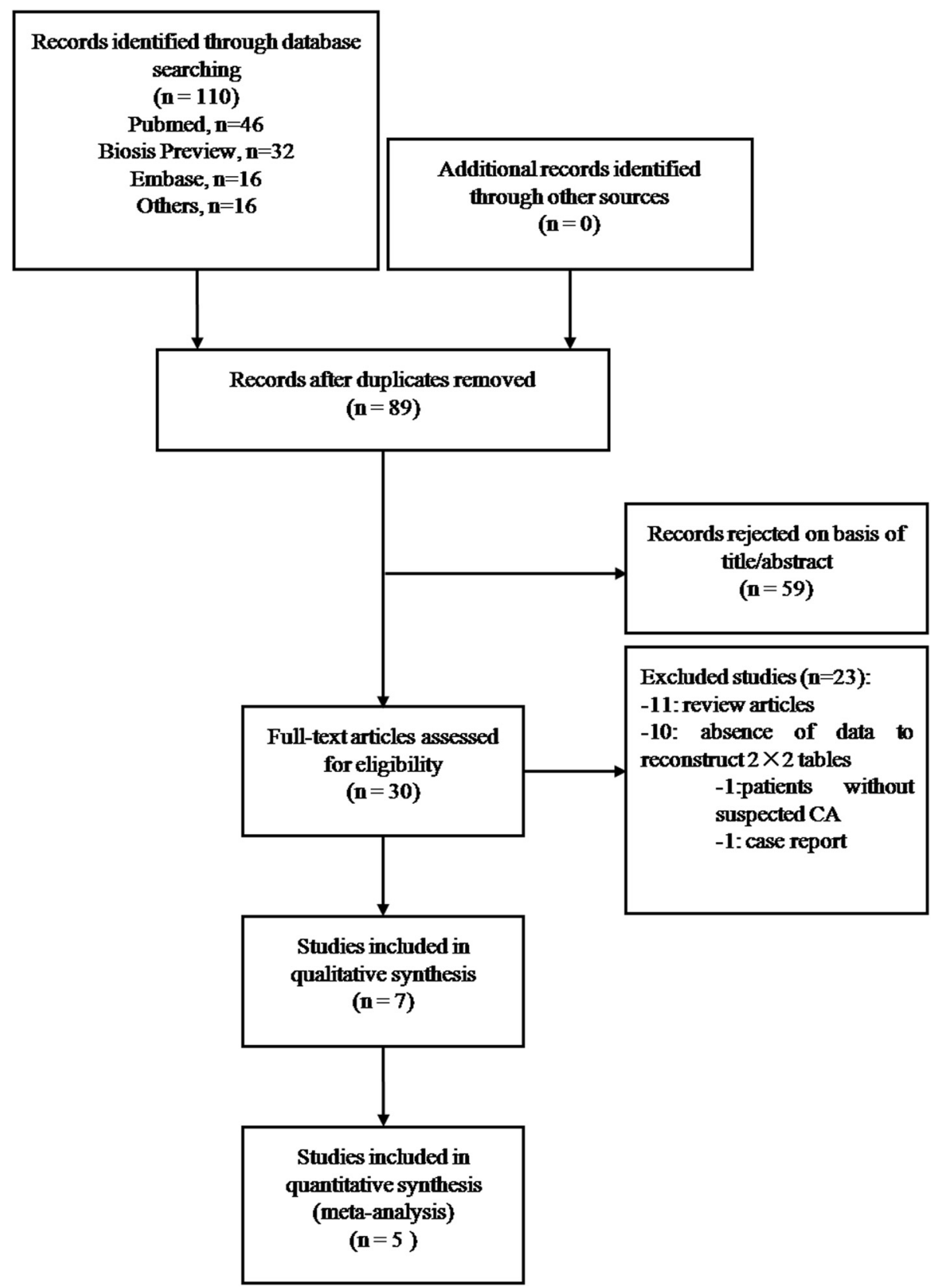

Fig. 1 Flow chart of selection process

patients and procedures were extracted from each primary study independently by two reviewers (LZ, ZT).

\section{Assessment of risk of bias}

Two reviewers (LZ, ZT) appraised the methodological quality based on the form suggested by the Quality Assessment of Diagnostic Accuracy Studies-2 (QUADAS2 ), which has main parts: patient selection, index test, reference standards, and the flow and timing [14]. Each part involves the assessment of risk of bias (low, high, or unclear) and first 3 parts also need to evaluate the clinical applicability. In cases of disagreement, 2 reviewers would reach a consensus after a thorough discussion with a third person (QF).

\section{Statistical analysis}

Statistical analyses were conducted using MetaDisc 1.4 software and Review Manager software version 5.3. First, heterogeneity in included manuscripts was assessed in terms of Cochran $\mathrm{Q}$ chi-square tests and $\mathrm{I}^{2}$ statistics. In cases of significant heterogeneity, the random-effects model was suitable to pool several parameters and 
sensitivity analysis was used to investigate potential sources targeting risk bias calculated by QUADAS-2. In other cases, the Mantel-Haenszel method was used to establish a fixed-effects model during the evaluation process. In cases of implicit threshold effects, the Spearman rank correlation was taken into consideration. Subgroup analysis determined if there was a correlation between sensitivity and specificity. Second, positive likelihood ratios (PLR), negative likelihood ratios (NLR), and diagnostic odds ratio (DOR), and their $95 \%$ confidence intervals $(\mathrm{CI})$ were estimated based on pooled sensitivity and specificity. In order to estimate the overall diagnostic effect, a summary receiver operating characteristic (SROC) curve was established, with pertinent areas. Whenever a study's data contained zero counts, 0.5 was added as a continuity correction. Any significantly statistical calculating was at a two-sided 0.05 level.

\section{Results}

The systematical electronic search identified 110 publications, of which 46, 32, 16, 10, 5, and 1 were found in Pubmed, Biosis Preview, Embase, ISI Web of Science, Cochrane Library and China National Knowledge Infrastructure. Figure 1 outlines the process of manuscripts screening. Here, 21 studies were excluded because of duplicate records. After the removal of 59 studies whose titles or abstracts did not meet the inclusion criteria, only
30 full-text articles were retained for further evaluation. Of the 30 potentially appropriate publications, only 7 were included in the systematic review [15-21]. Most of the excluded studies were reviews or did not provide absolute figures. The meta-analysis was performed on 5 studies that focused on the LGE performance [17-21].

\section{Methodological evaluation}

Figure 2 shows the graphs of risk bias and concerns about clinical application evaluated by QUADAS-2. In the patient selection domain, one report did not state that patients were enrolled in a consecutive pattern [20]. Another study lacked relevant information on patient sampling [16]. The Karamitsos and Hosch studies both used a case-control design [15]. In terms of an inappropriate exclusion, both Karamitsos and Hosch's studies were unclear. Regarding interpretation of the CMR results, 2 studies did not clearly state whether they were conducted before knowing the results of EMB, the one by Karamitsos and another one by Austin [19]. LGE-CMR was used in 6 studies, and one study used MR-relaxometry to evaluate $\mathrm{T} 1$ and $\mathrm{T} 2$ relaxation time (RT), which established a cutoff value of $1273 \mathrm{~ms}$ of T1-RT to diagnose CA with a high sensitivity and specificity [15]. The other 6 studies detailed the LGE-CMR procedures and defined amyloid LGE pattern using long and short axes images in the ventricular area without coronary artery distribution [16-21]. No

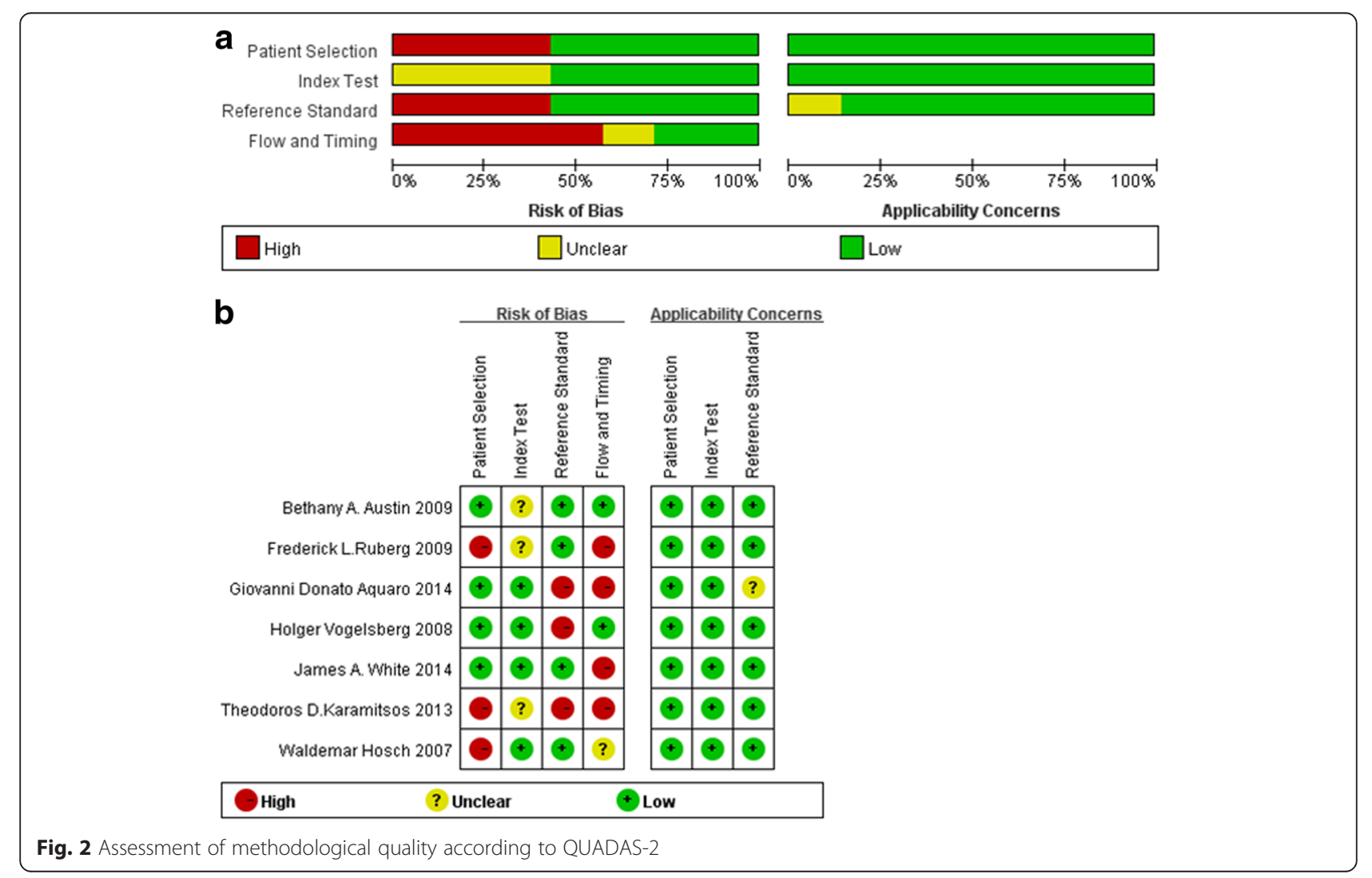


concerns about the included patients going against the inclusion criteria.

There were 2 studies that did not clearly report that the EMB evaluation was blinded to CMR results $[19,21]$. Another study stated it was done without blindness [17]. In terms of the reference tests, some patients could not be classified clearly using clinical criteria alone [16, 21]. This kind of study involved high risk bias and uncertainty regarding use in the reference domain.

One study was discarded because of incomplete data for $2 \times 2$ table [16]. The interval between CMR and the reference test were only clearly stated in 3 studies $[17,19,21]$. But these 3 studies together did not use the same reference test on all the patients. Some patients were evaluated by EMB and others were clinically assessed using ECG, echocardiography, or both. In the study by White, only 25 (28\%) patients with suspected CA were included in the final diagnostic evaluation [18].
Overall, all the included studies involved little concerns regarding applicability and remaining 5 studies were here considered methodologically correct regardless of risk bias [17-21].

\section{Study characteristics}

The baseline characteristics of these included studies are shown in Table 1 [15-21]. A total of 485 subjects were recruited in the final systematic analysis. These manuscripts were published during the period from 2007 to 2014 and four of them were prospective studies $[15,18$, $20,21]$. Patients involved in individual studies are summarized concisely in Table 1 . The sample size ranged from 28 to 106 and the mean age was similarly around 62 years old. Mean time intervals were only available in three studies $[17,19,21]$. Six studies used EMB as a reference test [15, 17-21]. Another one used echocardiography and clinical features as to classify patients [16]. All studies used 1.5-T scanners to perform the CMR, but

Table 1 Characteristics of included studies

\begin{tabular}{|c|c|c|c|c|c|c|c|c|c|c|c|}
\hline Study & Year & Country & $\begin{array}{l}\text { Study } \\
\text { design }\end{array}$ & Population & Age, yrs & $\begin{array}{l}\text { Male, } \\
\mathrm{n}\end{array}$ & $\begin{array}{l}\text { Mean time } \\
\text { interval }^{a}\end{array}$ & Blind $^{b}$ & Reference test & $\begin{array}{l}\text { Index } \\
\text { measured } \\
\text { using CMR }\end{array}$ & $\begin{array}{l}\text { Field } \\
\text { strength }\end{array}$ \\
\hline $\begin{array}{l}\text { Hosch } \\
\text { et al. }\end{array}$ & 2007 & Germany & $P C$ & $\begin{array}{l}19 \text { with newly } \\
\text { diagnosed CA and } 9 \\
\text { patients with systemic } \\
\text { amyloidosis but } \\
\text { without CA and } 10 \\
\text { healthy, age-matched } \\
\text { control }\end{array}$ & $59 \pm 6.1$ & 14 & NA & Y & EMB & $\mathrm{T} 1$ and $\mathrm{T} 2 \mathrm{RT}$ & $1.5 \mathrm{~T}$ \\
\hline $\begin{array}{l}\text { Vogelsberg } \\
\text { et al. }\end{array}$ & 2008 & Germany & NA & $\begin{array}{l}33 \text { subjects with } \\
\text { suspected CA }\end{array}$ & $64 \pm 13$ & NA & Same day & Y & EMB & $\begin{array}{l}\text { Amyloid LGE } \\
\text { pattern }\end{array}$ & $1.5 \mathrm{~T}$ \\
\hline $\begin{array}{l}\text { Austin } \\
\text { et al. }\end{array}$ & 2009 & USA & $\mathrm{RC}$ & $\begin{array}{l}47 \text { subjects with } \\
\text { suspected CA }\end{array}$ & 62 & 33 & $24-48 h$ & $\mathrm{~N}$ & EMB & LGE; DHE & $1.5 \mathrm{~T}$ \\
\hline $\begin{array}{l}\text { Ruberg } \\
\text { et al. }\end{array}$ & 2009 & USA & $P C$ & $\begin{array}{l}28 \text { patients with } \\
\text { systemic } A L \\
\text { amyloidosis }\end{array}$ & $62 \pm 11$ & 20 & NA & Y & $\begin{array}{l}\text { EMB or clinical } \\
\text { criteria }\end{array}$ & LGE & $1.5 \mathrm{~T}$ \\
\hline $\begin{array}{l}\text { Karamitsos } \\
\text { et al. }\end{array}$ & 2013 & $\begin{array}{l}\text { UK } \\
\text { Canada }\end{array}$ & NA & $\begin{array}{l}53 \text { patients with } \\
\text { systemic (primary) AL } \\
\text { amyloidosis and } 17 \\
\text { patients with aortic } \\
\text { stenosis and } 36 \\
\text { normal volunteers }\end{array}$ & $63 \pm 10^{c}$ & 69 & NA & Y & $\begin{array}{l}\text { Echocardiography } \\
\text { and clinical features }\end{array}$ & $\begin{array}{l}\text { Noncontrast T1 } \\
\text { mapping; LGE }\end{array}$ & $1.5 \mathrm{~T}$ \\
\hline $\begin{array}{l}\text { Aquaro } \\
\text { et al. }\end{array}$ & 2014 & Italy & PC & $\begin{array}{l}59 \text { patients with a } \\
\text { previous diagnosis of } \\
\text { systemic AL } \\
\text { amyloidosis and } 20 \\
\text { healthy control } \\
\text { subjects }\end{array}$ & $69 \pm 10$ & 36 & Same day & Y & $\begin{array}{l}\text { Echocardiographic } \\
\text { criteria and/or ECG } \\
\text { criteria or EMB }\end{array}$ & $\begin{array}{l}\text { SID; } \\
\text { conventional } \\
\text { LGE }\end{array}$ & $1.5 \mathrm{~T}$ \\
\hline $\begin{array}{l}\text { White } \\
\text { et al. }\end{array}$ & 2014 & USA & PC & $\begin{array}{l}90 \text { patients with } \\
\text { suspected CA and } 64 \\
\text { hypertensive patients } \\
\text { with LVH }\end{array}$ & $62 \pm 13$ & 52 & NA & Y & EMB & $\begin{array}{l}\text { LGE pattern: } \\
\text { Global HE }\end{array}$ & $1.5 \mathrm{~T}$ \\
\hline
\end{tabular}

$A L$ amyloid light-chain, $C A$ cardiac amyloidosis, DHE delayed hyper-enhancement, ECG echocardiography, $H E$ hyperenhancement, $E M B$ endomyocardial biopsy, $L G E$ late gadolinium enhancement, $L V H$ left ventricular hypertrophy, $N$ no, $N A$ not available, $P C$ prospective cohort, $R C$ retrospective cohort, $R T$ relaxation times, SID signal intensity decay

${ }^{a}$ Time interval between reference tests and cardiac magnetic resonance

${ }^{\mathrm{b}}$ The CMR results were interpreted blind to the results of the reference tests or the reference tests were performed without knowing the results of cardiac magnetic resonance

${ }^{\mathrm{c} A m y l o i d ~ p a t i e n t s ~ w i t h ~ d e f i n i t e ~ c a r d i a c ~ i n v o l v e m e n t ~}$ 
only five of them evaluated the diagnostic accuracy of LGE by calculating sensitivity and specificity [17-21]. No adverse events were reported in the examinations.

\section{Diagnostic performance of CMR for CA}

Five studies contained absolute figures for $2 \times 2$ tables with respect to LGE and were included in the metaanalysis (Table 2) [17-21]. Individual studies are shown on forest plots focusing on sensitivity and specificity. The $X^{2}$ test for sensitivity and specificity produced a $P$ value of 0.2003 and 0.0581 with $\mathrm{I}^{2}$ values of $33.2 \%$ and $56.1 \%$, respectively. In cases with a detectable threshold effect, the Spearman rank correlation between the sensitivity and 1-specifity was performed and the correlation coefficient was 0.8 with a $P$ value 0.104 (Additional files 1 and 2). Because the inconsistency index $\mathrm{I}^{2}$ was used to quantify the heterogeneity, an $\mathrm{I}^{2}$ value of $56.1 \%$ was considered moderate (50-74\%). For this reason, the random-effects model was used for the meta-analysis.

As shown in Fig. 3, the pooled sensitivity and specificity of LGE-CMR were $85 \%$ (95\% CI: 77-93\%) and 92 \% (95 \% CI: 83-97 \%). The pooled positive likelihood ratio was 7.481 (95\% CI: 2.835-19.739) and the negative one was 0.183 (95\% CI: $0.121-0.277$ ). Figure 4 shows the SROC curve for LEG-CMR, suggesting the LGE is an effective mean of diagnosing patients with amyloidosis and potential cardiac involvement. These results also corresponded to the pooled diagnostic odd ratio (Fig. 5). There was some residual heterogeneity in the diagnostic accuracy. Sensitivity analysis was conducted to determine the source of heterogeneity. After removing the study by Aquaro which involved high risk bias in the methodological evaluation, results showed the specificity have an $\mathrm{I}^{2}$ value of $9.3 \%$ and $P$ value of 0.3467 [21]. However, this did not change the direction or magnitude of the pooled estimates, which means that the results of relatively good quality. Because only 5 publications were included, no funnel plot was constructed to assess publication bias.

\section{Discussion}

Amyloidosis, when it affects the heart, has a poor prognosis. Better diagnostic tests would permit earlier detection and therefore targeted intervention to improve outcomes. Many modalities have been used in clinical settings to detect and evaluate CA [22]. The most common methods are ECG and echocardiography. These tools are convenient and available in most medical facilities in which the EMB is not in common use. However, both methods detect CA with a relatively low accuracy. ECG evaluation is not suitable for patients with pulmonary disorders but many patients with cardiomyopathy, especially elderly patients, are likely to be involved in cardiopulmonary diseases. Echocardiography can detect the advanced cases [23]. However, it cannot easily assess earlier cases or differentiate CA from hypertrophic cardiomyopathy because the characteristics in echocardiography are thick-walled ventricles with speckled myocardia [4, 23]. EMB is considered the gold standard in the diagnosis of CA. However, the unavailability, relatively high risks and clinical complications may hinder its widespread use in clinical settings. CMR provides a third option in the evaluation of the heart's structure and assessment of its diastolic function. It is more precise and more accurate, which are regarded as the hallmarks of good non-invasive methods capable of assessing myocardial scars $[13,24]$.

The key advantage of using CMR to detect the CA is its unique ability to describe the characteristics of heart, which can be done particularly using LGE [25]. After taking the gadolinium-based contrast, patients with CA presented typical global subendocardial enhancement patterns, which are closely associated with interstitial amyloid burden and often used to qualitatively detect focal fibrosis [26]. This meta-analysis of LGE-CMR

Table 2 Cardiac magnetic resonance evaluation of the included studies in the systematic review

\begin{tabular}{|c|c|c|c|c|c|c|c|c|c|c|c|}
\hline Study & Number of subjects & Index measured using CMR & TF & $\mathrm{FP}$ & $\mathrm{FN}$ & TN & Sensitivity (\%) & Specificity (\%) & PPV (\%) & NPV (\%) & $A \cup C$ \\
\hline \multirow[t]{2}{*}{ Hosch et al. } & \multirow[t]{2}{*}{38} & \multirow[t]{2}{*}{ T1-RT } & $16^{\mathrm{a}}$ & $0^{a}$ & $3^{a}$ & $10^{a}$ & $84^{\mathrm{a}}$ & $100^{\mathrm{a}}$ & $N A^{a}$ & $N A^{a}$ & $0.96^{\mathrm{a}}$ \\
\hline & & & $16^{\mathrm{b}}$ & $1^{\mathrm{b}}$ & $3^{b}$ & $8^{b}$ & $84^{b}$ & $89^{b}$ & $N A^{b}$ & $N A^{b}$ & $0.89^{b}$ \\
\hline Vogelsberg et al. & 33 & LGE & 12 & 1 & 3 & 17 & 80 & 94 & 92 & 85 & NA \\
\hline Austin et al. & 47 & LGE & 15 & 2 & 2 & 19 & 88 & 90 & 88 & 90 & NA \\
\hline Ruberg et al. & 28 & LGE & 18 & 1 & 3 & 6 & 86 & 86 & 95 & 67 & NA \\
\hline Karamitsos et al. & 106 & Noncontrast T1 mapping & 36 & 6 & 3 & 61 & 92 & 91 & NA & NA & NA \\
\hline \multirow[t]{2}{*}{ Aquaro et al. } & \multirow[t]{2}{*}{79} & SID & 51 & 2 & 1 & 26 & 98 & 93 & 96 & 96 & NA \\
\hline & & LGE & 42 & 0 & 10 & 27 & 81 & 100 & 100 & 73 & NA \\
\hline White et al. & 154 & LGE & 15 & 3 & 0 & 7 & 93 & 70 & NA & NA & NA \\
\hline
\end{tabular}

$A U C$ area under receiver-operating characteristic curve, $F N$ false negative, $F P$ false positive, $T N$ true negative, $T P$ true positive, $P P V$ positive predictive value, $N A$ not available, NPV negative predictive value, LGE late gadolinium enhancement, $R T$ relaxation time, SID signal intensity decay ${ }^{a} \mathrm{CA}$ patients compared with the healthy, age-matched control group

${ }^{\mathrm{b}} \mathrm{CA}$ patients compared with the patient group with systemic amyloidosis but without cardiac involvement 


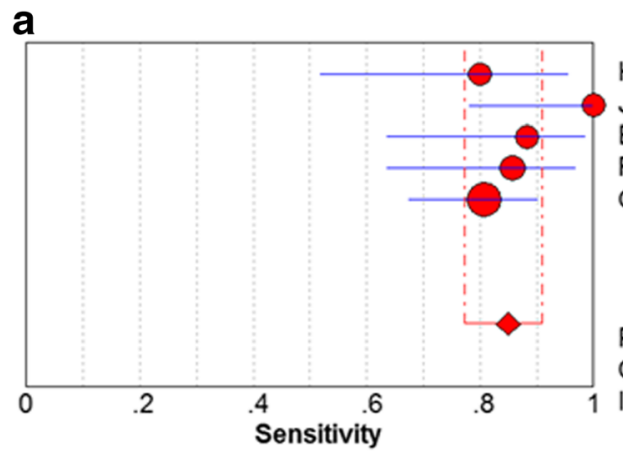

b

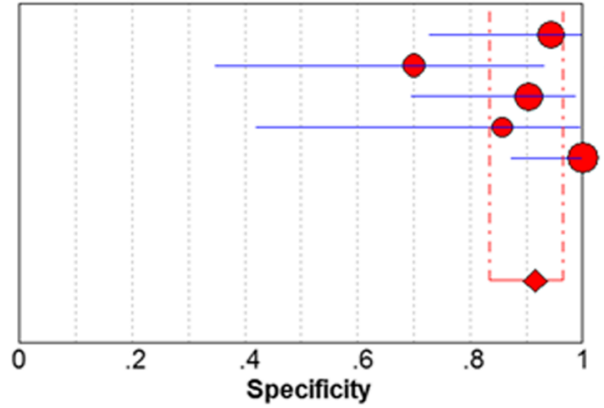

Holger Vogelsberg

James A. White

Bethany A. Austin

Frederick L. Ruberg

Giovanni Donato Aquaro
Sensitivity $(95 \% \mathrm{Cl})$

$0.80 \quad(0.52-0.96)$

$1.00 \quad(0.78-1.00)$

$0.88 \quad(0.64-0.99)$

$0.86 \quad(0.64-0.97)$

$0.81 \quad(0.67-0.90)$

Pooled Sensitivity $=0.85(0.77$ to 0.91$)$

Chi-square $=5.98 ; \mathrm{df}=4(p=0.2003)$

Inconsistency (I-square) $=33.2 \%$

Holger Vogelsberg

James A. White

Bethany A. Austin

Frederick L. Ruberg

Specificity $(95 \% \mathrm{Cl})$

Giovanni Donato Aquaro

$0.94 \quad(0.73-1.00)$

$0.70 \quad(0.35-0.93)$

$0.90 \quad(0.70-0.99)$

$0.86 \quad(0.42-1.00)$

$1.00 \quad(0.87-1.00)$

Pooled Specificity $=0.92(0.83$ to 0.97$)$

Chi-square $=9.12 ; \mathrm{df}=4(\mathrm{p}=0.0581)$

Inconsistency (I-square) $=56.1 \%$

Fig. 3 Forest plot evaluating the sensitivity and specificity of diagnostic performance of late gadolinium enhancement in included studies. $\mathrm{Cl}$, confidence interval

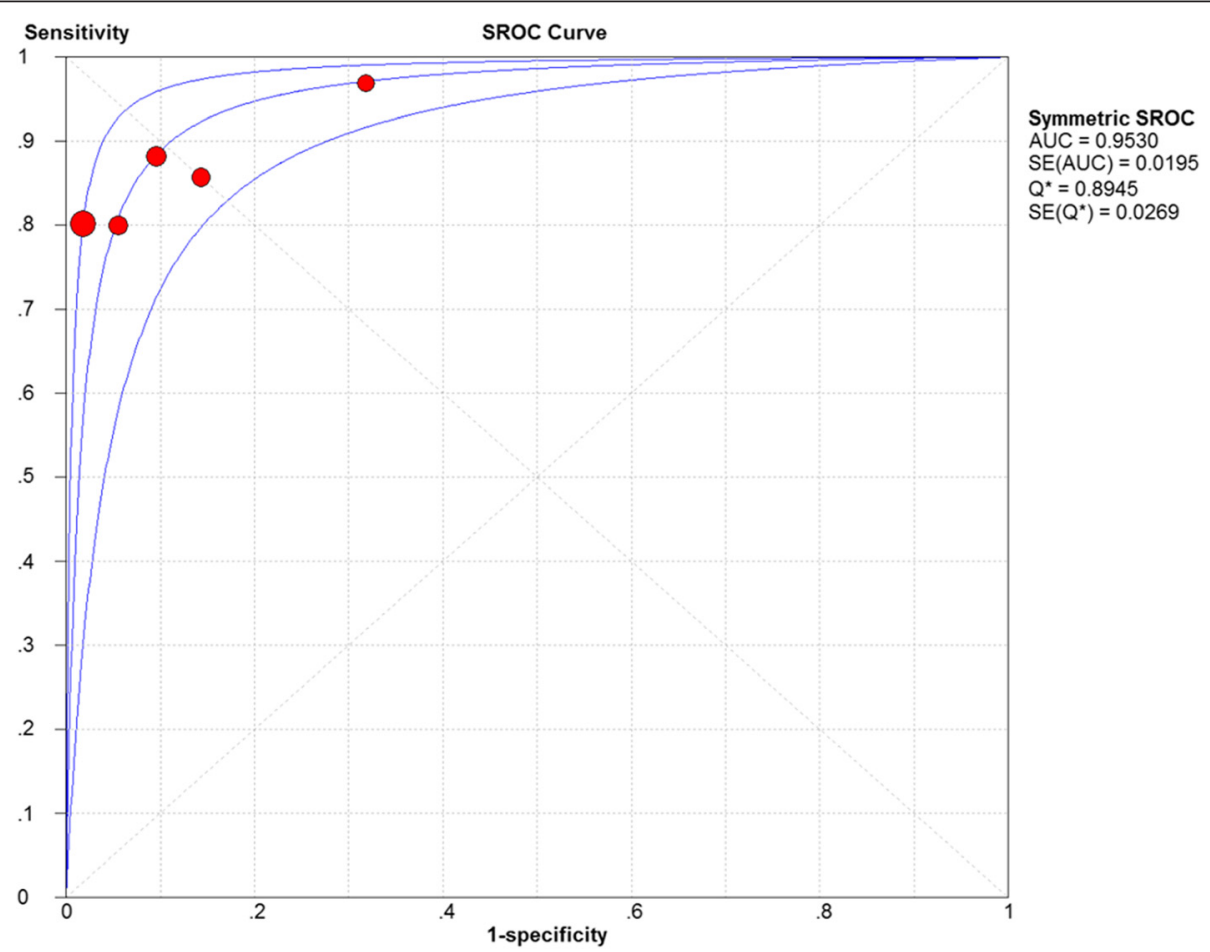

Fig. 4 Summary receiver operator characteristics (SROC) of late gadolinium enhancement on summary estimates of sensitivity and specificity. AUC, area under the curve; SE, standard error 


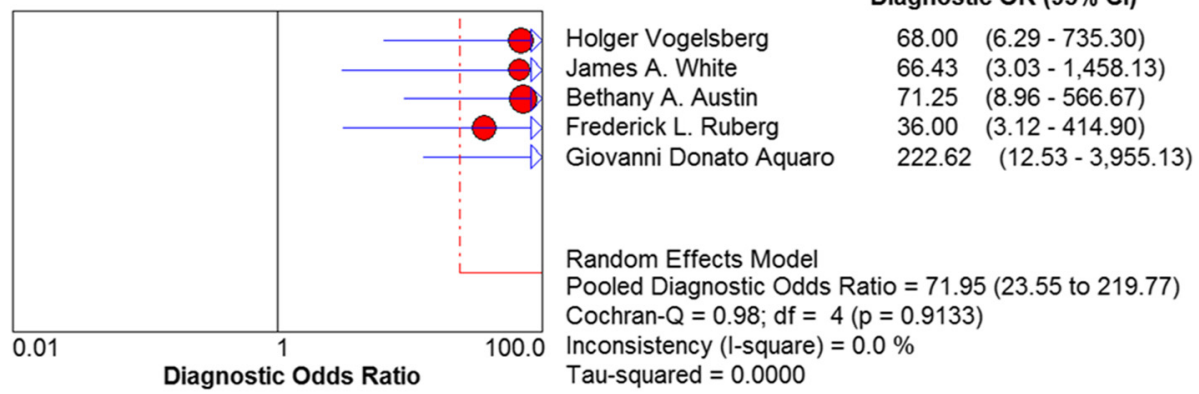

Fig. 5 Forest plot presenting the pooled diagnostic odds ratio of late gadolinium enhancement. Cl, confidence interval

showed that the diagnostic accuracy increased with a summary sensitivity of $85 \%$ and a summary specificity of $92 \%$. In terms of the heart tissue characterization, LGE can distinguish CA patients from healthy controls with a summary positive likelihood ratio of 7.481 (95\% CI: 2.835-19.739). The summary diagnostic odds ratio of 71.945 detected here (95 \% CI: 23.552-219.77) indicated that expressed the test was more accurate in the differential diagnosis of CMR than other types of diagnosis. In this way, the values of LR+ and DOR favor of LEG-CMR in patients with suspected CA before EMB. Heterogeneity was observed across studies in terms of specificity, but not sensitivity. This could be partially due to the methodological quality of involved publications on reference tests choosing and flow and timing.

$\mathrm{AL}$ and ATTR are two types of amyloidosis typically associated with the heart. ATTR is often underdiagnosed and can be fatal. It also has particular variants in specific ethnic populations, which makes diagnosing and typing both necessary and challenging. Recently, several studies have reported that the new CMR techniques have better diagnostic accuracy in demonstrating the range of structural and functional changes in different types of CA [27]. T1 mapping, a new technique measuring myocardial intrinsic signal, was found to diagnose $\mathrm{AL}$ and ATTR very accurately [28, 29]. Native T1 levels were higher in ATTR patients than in controls and the area under the AUC for ATTR and AL patients with possible or definite cardiac involvement was 0.85 (95 \% CI: 0.790.92) [29]. One study reviewed here evaluated the noncontrast myocardial T1, and the cut-off of $1020 \mathrm{~ms}$ yielded $92 \%$ accuracy for identifying CA [16]. T1-RT reported by Hosch also diagnosed CA with a high sensitivity $(84 \%)$ and specificity (>89 \%) with a cut-off value of $\geq 1273 \mathrm{~ms}$ [15]. The measurement of extracellular volume (ECV) measurement is popular in some centers $[30,31] . \mathrm{ECV}$ is elevated in both AL and ATTR, which helps the evaluation of amyloid burden. It is also elevated in patients where routine examinations, including LGE, indicated no heart involvement. In the present systematic review, one study analyzed the myocardial signal intensity decay (SID) at the subendocardial level after gadolinium injection, showing a greater accuracy (96\%) and sensitivity (98\%) for CA assessment than LGE with a $269 \mathrm{HB}$ threshold [21]. T1 values were higher in AL amyloid than in ATTR, but ECV was higher in ATTR [12]. This suggests that combined T1 and ECV techniques may attach more diagnostic accuracy to patients with cardiac involvement, quantify the amyloid burden to evaluate the pathologic conditions, and distinguish types of CA to help clinicians select the most appropriate treatment for each patient. When LGE combine with these advanced techniques, CMR could be a main technique for the diagnosis of patients with potential CA.

The current review has some limitations, which should be taken into consideration. The main one is the small number of studies included, which restricted deep exploration of potential sources of heterogeneity. The second limitation is that the typical amyloid LGE pattern varies across different series. Localized enhancement, diffuse transmural or patchy LGE enhancement was reported in different studies. In this review, only three studies described the diffuse, global subendocardial enhancement pattern as the amyloid pattern. The third limitation is that not all of the studies used the same reference tests. Not all patients underwent the same reference tests, introducing selection bias in the final results. Despite these limitations, the current work can present the current state of diagnostic tests of CMR for CA, which may help medical workers choose diagnostic methods efficiently and effectively.

\section{Conclusion}

The current work indicates that the LGE is more accurate in the diagnosis of CA, which makes it valuable in the detection of amyloid deposit. However, when considering clinical cost-effectiveness and patients with claustrophobia, implanted cardiac devices and renal failure, CMR application value in CA needs further investigation. 


\section{Additional files}

Additional file 1: Search strategy. (DOCX $142 \mathrm{~kb}$ )

Additional file 2: Summary indexes in the meta-analysis. (DOCX $15 \mathrm{~kb}$ )

\section{Abbreviations}

$\mathrm{AL}$, amyloid light chain; ATTR, amyloid transthyretin; AUC, area under the curve; CA, cardiac amyloidosis; Cl, confidence intervals; CMR, Cardiovascular magnetic resonance; DOR, Diagnostic odds ratio; ECG, Electrocardiography; ECV, extracellular volume; EMB, Endomyocardial biopsy; LGE, late gadolinium enhancement; NLR, negative likelihood ratios; PLR, positive likelihood ratios; PSIR, phase-sensitive inversion recovery; QUADAS-2, Quality Assessment of Diagnostic Accuracy Studies-2; RT, relaxation time; SID, signal intensity decay; SROC, Summary receiver operating characteristics

\section{Funding}

This research received no grant from any funding agency in the public, commercial or not-for-profit sectors.

\section{Availability of data and materials}

All the data supporting findings is contained within the manuscript.

\section{Author's contributions}

LZ participated in the study design and data analysis and drafted the manuscript. ZT helped in the coordination and helped draft the manuscript. QF helped draft the manuscript. All authors read and approved the final manuscript.

\section{Competing interests}

The authors declare that they have no competing interests.

\section{Consent for publication}

Not applicable.

\section{Ethics approval and consent to participate}

Not applicable.

Received: 11 July 2015 Accepted: 31 May 2016

Published online: 07 June 2016

\section{References}

1. Rapezzi C, Lorenzini M, Longhi S, Milandri A, Gagliardi C, Bartolomei I, Salvi F, Maurer MS. Cardiac amyloidosis: the great pretender. Heart Fail Rev. 2015:20:117-24.

2. Sipe JD, Benson MD, Buxbaum JN, Ikeda S, Merlini G, Saraiva MJ, Westermark P. Amyloid fibril protein nomenclature: 2012 recommendations from the Nomenclature Committee of the International Society of Amyloidosis. Amyloid. 2012:19:167-70.

3. Gertz MA, Dispenzieri A, Sher T. Pathophysiology and treatment of cardiac amyloidosis. Nat Rev Cardiol. 2015;12:91-102.

4. Mohty D, Damy T, Cosnay P, Echahidi N, Casset-Senon D, Virot P, Jaccard A. Cardiac amyloidosis. Updates in diagnosis and management. Arch Cardiovasc Dis. 2013:106:528-40.

5. Yusuf SW, Solhpour A, Banchs J, Lopez-Mattei JC, Durand J, Iliescu C, Hassan SA, Qazilbash MH. Cardiac amyloidosis. Expert Rev Cardiovasc Ther. 2014;12:265-77.

6. Sharma N, Howlett J. Current state of cardiac amyloidosis. Curr Opin Cardiol. 2013;28:242-8

7. Quarta CC, Solomon SD, Uraizee I, Kruger J, Longhi S, Ferlito M, Gagliardi C, Milandri A, Rapezzi C, Falk RH. Left ventricular structure and function in transthyretin-related versus light-chain cardiac amyloidosis. Circulation. 2014;129:1840-9.

8. Sher T, Gertz MA. Recent advances in the diagnosis and management of cardiac amyloidosis. Futur Cardiol. 2014;10:131-46.

9. Yancy $\mathrm{CW}$, Jessup M, Bozkurt B, Butler J, Casey DE, Drazner MH, Fonarow GC, Geraci SA, Horwich T, Januzzi JL, Johnson MR, Kasper EK, Levy WC, Masoudi FA, McBride PE, McMurray JJ, Mitchell JE, Peterson PN, Riegel B, Sam F, Stevenson LW, Tang WH, Tsai EJ, Wilkoff BL, American College of Cardiology Foundation, American Heart Association Task Force on Practice Guidelines. 2013 ACCF/AHA Guideline for the Management of Heart Failure. Am Coll Cardiol. 2013;62:e147-239.
10. Murtagh B, Hammill SC, Gertz MA, Kyle RA, Tajik AJ, Grogan M. Electrocardiographic findings in primary systemic amyloidosis and biopsyproven cardiac involvement. Am J Cardiol. 2005;95:535-7.

11. Cappelli F, Baldasseroni S, Bergesio F, Perlini S, Salinaro F, Padeletti L, Attana P, Paoletti PA, Moggi PA, Grifoni E, Fabbri A, Marchionni N, Gensini GF, Perfetto F. Echocardiographic and biohumoral characteristics in patients with AL and TTR amyloidosis at diagnosis. Clin Cardiol. 2015;38:69-75.

12. Fontana M, Chung R, Hawkins PN, Moon JC. Cardiovascular magnetic resonance for amyloidosis. Heart Fail Rev. 2015;20:133-44.

13. Syed IS, Glockner JF, Feng D, Araoz PA, Martinez MW, Edwards WD, Gertz MA, Dispenzieri A, Oh JK, Bellavia D, Tajik AJ, Grogan M. Role of Cardiac Magnetic Resonance Imaging in the Detection of Cardiac Amyloidosis. J Am Coll Cardiol Img. 2010:3:155-64.

14. Whiting PF, Rutjes AW, Westwood ME, Mallett S, Deeks JJ, Reitsma JB, Leeflang MM, Sterne JA, Bossuyt PM. QUADAS-2: a revised tool for the quality assessment of diagnostic accuracy studies. Ann Intern Med. 2011;155:529-36.

15. Hosch W, Bock M, Libicher M, Ley S, Hegenbart U, Dengler TJ, Katus HA, Kauczor HU, Kauffmann GW, Kristen AV. MR-relaxometry of myocardia tissue: significant elevation of T1 and T2 relaxation times in cardiac amyloidosis. Invest Radiol. 2007:42:636-42.

16. Karamitsos TD, Piechnik SK, Banypersad SM, Fontana M, Ntusi NB, Ferreira VM, Whelan CJ, Myerson SG, Robson MD, Hawkins PN, Neubauer S, Moon JC. Noncontrast T1 Mapping for the Diagnosis of Cardiac Amyloidosis. J Am Coll Cardiol Img. 2013;6:488-97.

17. Vogelsberg H, Mahrholdt H, Deluigi CC, Yilmaz A, Kispert EM, Greulich S, Klingel K, Kandolf R, Sechtem U. Cardiovascular Magnetic Resonance in Clinically Suspected Cardiac Amyloidosis. J Am Coll Cardiol. 2008;51:1022-30.

18. White JA, Kim HW, Shah D, Fine N, Kim K, Wendell DC, Al-Jaroudi W, Parker M, Patel M, Gwadry-Sridhar F, Judd RM, Kim RJ. CMR Imaging With Rapid Visual T1 Assessment Predicts Mortality in Patients Suspected of Cardiac Amyloidosis. J Am Coll Cardiol Img. 2014;7:143-56.

19. Austin BA, Tang WHW, Rodriguez ER, Tan C, Flamm SD, Taylor DO, Starling RC, Desai MY. Delayed Hyper-Enhancement Magnetic Resonance Imaging Provides Incremental Diagnostic and Prognostic Utility in Suspected Cardiac Amyloidosis. J Am Coll Cardiol Img. 2009:2:1369-77.

20. Ruberg FL, Appelbaum E, Davidoff R, Ozonoff A, Kissinger KV, Harrigan C, Starling RC, Desai MY. Diagnostic and Prognostic Utility of Cardiovascular Magnetic Resonance Imaging in Light-Chain Cardiac Amyloidosis. Am J Cardiol. 2009;103:544-9.

21. Aquaro GD, Pugliese NR, Perfetto F, Cappelli F, Barison A, Masci PG, Passino C, Emdin M. Myocardial signal intensity decay after gadolinium injection: a fast and effective method for the diagnosis of cardiac amyloidosis. Int J Cardiovasc Imaging. 2014;30:1105-15.

22. Di Bella G, Pizzino F, Minutoli F, Zito C, Donato R, Dattilo G, Oreto G, Baldari S, Vita G, Khandheria BK, Carerj S. The mosaic of the cardiac amyloidosis diagnosis: role of imaging in subtypes and stages of the disease. Eur Heart J Cardiovasc Imaging. 2014;15:1307-15.

23. Nakahashi T, Arita T, Yamaji K, Inoue K, Yokota T, Hoshii Y, Fukunaga M, Nomura A, Watanabe H, Miura S, Isotani A, Soga Y, Ando K, Iwabuchi M, Yokoi H, Nosaka H, Yamagishi M, Nobuyoshi M. Impact of clinical and echocardiographic characteristics on occurrence of cardiac events in cardiac amyloidosis as proven by endomyocardial biopsy. Int J Cardiol. 2014;176:753-9.

24. Deux JF, Damy T, Rahmouni A, Mayer J, Plante-Bordeneuve V. Noninvasive detection of cardiac involvement in patients with hereditary transthyretin associated amyloidosis using cardiac magnetic resonance imaging: a prospective study. Amyloid. 2014;21:246-55.

25. Maceira AM. Cardiovascular Magnetic Resonance in Cardiac Amyloidosis Circulation. 2005:111:186-93.

26. Syed IS, Glockner JF, Feng D, Araoz PA, Martinez MW, Edwards WD, Gertz MA Dispenzieri A, Oh JK, Bellavia D, Tajik AJ, Grogan M. Role of cardiac magnetic resonance imaging in the detection of cardiac amyloidosis. JACC Cardiovasc Imaging. 2010;3:155-64

27. Dungu JN, Valencia O, Pinney JH, Gibbs SD, Rowczenio D, Gilbertson JA Lachmann HJ, Wechalekar A, Gillmore JD, Whelan CJ, Hawkins PN, Anderson L. CMR-based differentiation of AL and ATTR cardiac amyloidosis. JACC Cardiovasc Imaging. 2014;7:133-42.

28. Banypersad SM, Fontana M, Maestrini V, Sado DM, Captur G, Petrie A Piechnik SK, Whelan CJ, Herrey AS, Gillmore JD, Lachmann HJ, Wechalekar AD, Hawkins PN, Moon JC. T1 mapping and survival in systemic light-chain amyloidosis. Eur Heart J. 2015;36:244-51. 
29. Fontana M, Banypersad SM, Treibel TA, Maestrini V, Sado DM, White SK, Pica S, Castelletti S, Piechnik SK, Robson MD, Gilbertson JA, Rowczenio D, Hutt DF, Lachmann HJ, Wechalekar AD, Whelan CJ, Gillmore JD, Hawkins PN, Moon JC. Native T1 mapping in transthyretin amyloidosis. JACC Cardiovasc Imaging. 2014; $7: 157-65$

30. Banypersad SM, Sado DM, Flett AS, Gibbs SD, Pinney JH, Maestrini V, Cox AT, Fontana M, Whelan CJ, Wechalekar AD, Hawkins PN, Moon JC. Quantification of myocardial extracellular volume fraction in systemic AL amyloidosis: an equilibrium contrast cardiovascular magnetic resonance study. Circ Cardiovasc Imaging. 2013;6:34-9.

31. Mongeon FP, Jerosch-Herold M, Coelho-Filho OR, Blankstein R, Falk RH, Kwong RY. Quantification of extracellular matrix expansion by CMR in infiltrative heart disease. JACC Cardiovasc Imaging. 2012;5:897-907.

Submit your next manuscript to BioMed Central and we will help you at every step:

- We accept pre-submission inquiries

- Our selector tool helps you to find the most relevant journal

- We provide round the clock customer support

- Convenient online submission

- Thorough peer review

- Inclusion in PubMed and all major indexing services

- Maximum visibility for your research

Submit your manuscript at www.biomedcentral.com/submit
Biomed Central 